\title{
RESEARCH ON COW TRAFFIC IN FACILITIES WITH AUTOMATIC MILKING SYSTEMS
}

\author{
Maris Mangalis, Juris Priekulis, Girts Vernavs \\ Latvia University of Life Sciences and Technologies, Latvia \\ maris.mangalis@1lu.lv, juris.priekulis@1lu.lv, girtsvernavs@inbox.lv
}

\begin{abstract}
If cows are milked with AMS (Automatic milking systems), the motivation of cows to move for milking voluntarily is of great importance. Otherwise, they need to be driven, but for that additional labour force needs to be attracted. There are two factors that influence the willingness of cows to visit AMS: correct and balanced feeding, as well as rationally organized cow traffic in the barn. The purpose of the study was to compare two kinds of cow traffic: free traffic, when the cows can move freely in the feeding and recreation zones, as well as controlled (forced) traffic, when the movement of cows from one functional zone to another is regulated. The research was done in a commercial farm, where for different groups of cows both traffic systems were used- free, as well as controlled driving. Two groups of cows with a similar number of lactations and analogous average milk yields, but different driving systems were selected. The research was conducted within a period of two months. For the research, the data stored in the herd management system were used, as well as the time necessary for driving the "lazy "cows (which did not visit the milking robots in due time) was taken. The research shows that with controlled driving compared to free traffic, repeated visiting of AMS by already milked cows decreases almost four times, but as a result of it the useful loading of AMS essentially improves. Besides, the labour consumption necessary for driving the "lazy" cows decreases almost two times.
\end{abstract}

Keywords: milking, dairy cows, AMS, milking frequency, cow traffic.

\section{Introduction}

Today the application of milking robots or AMS becomes more popular. It essentially decreases the labour consumption in farms and improves the welfare of cows $[1 ; 2]$. It has already been proved long ago that transferring from milking twice to milking three times the milk yield increases by $3-10 \%$, but transferring to milking four times - even by $5-10 \%$ and more [3; 4]. Therefore, cows with small milk yield can be milked two times per day, but cows with higher milk yields should be milked 3-4 times per day [3]. With traditional milking methods (in stalls or milking parlours), it is difficult because it requires large labour consumption. Besides, application of AMS improves more efficient usage of forage, as well as ensures the obtaining of the data necessary for herd management.

Nevertheless, the successful application of AMS is based on the willingness of cows to visit the milking robot voluntarily. If it is necessary to drive the cows, it causes economic losses that are created by the attraction of additional labour force, as well as by a potential decrease of milk that could be obtained in case of more often milking [5; 6]. In order to stimulate the cows to visit AMS voluntarily, concentrated feed is used during milking. Still, the research shows that increase of concentrated feed at AMS does not increase the frequency of milking and does not influence the number of cows to be driven for milking [11]. Therefore, the efficiency of AMS operation depends also on different other factors, including technical and technological solutions.

First of all, it is regulated by the permission for milking, which is set for every cow depending on the stage of lactation and the expected milk yield [12]. Nevertheless, our previous research shows [13] that the actual milking frequency usually does not correspond to the pre-set milking interval, but it decreases, if the cows are milked 3-4 times per day [14].

The technological solution of cow traffic is of essential importance [15]. The cow free traffic, when the cows have free access to AMS, recreation zones and the feeding table, is the simplest. It is also the cheapest cow traffic solution, as it is not necessary to install additional fences and selection gates. However, the research in different countries $[7 ; 8 ; 16]$ shows that in this case approximately $5-15 \%$ of the total number of cows do not voluntarily visit AMS and therefore they must be driven.

Today, controlled cow traffic is the most popular. In such case, milking, recreation and feeding zones are separated by fences and selection gates. It gives a possibility that only the cows having the milking permission are driven to the milking zone and it reduces the load of AMS caused by repeated visiting of AMS by the cows which have already been milked. Additionally, the so-called "Feed First" driving principle is used. It means that the cows in the recreation zone have free access to the feeding 
table, but only the milking zone is separated. The research of the company De Laval shows [16] that in such cases the number of driven cows does not exceed $1 \%$ of the total number of cows in the herd.

Therefore, it can be concluded that the influence of the kind of cow driving on the frequency of visiting AMS has been widely researched, but in every definite variant it can be different. Besides, the necessary consumption of time for driving the "lazy" cows has not been determined.

\section{Materials and methods}

The research was conducted in a Latvian farm, where cows are handled loose and milked with nine AMS produced by the company GEA. The cows were divided in five groups and for milking of every group two robots were used. The exception was the group of the first lactation cows served by one AMS. For the research, two groups of cows with similar lactation and analogous average milk yields were selected. In the first group (Group A) there were 97 cows, and the free traffic system was used. In the second group (Group B) there were 96 cows, and the controlled driving system was used, given in Fig. 1.

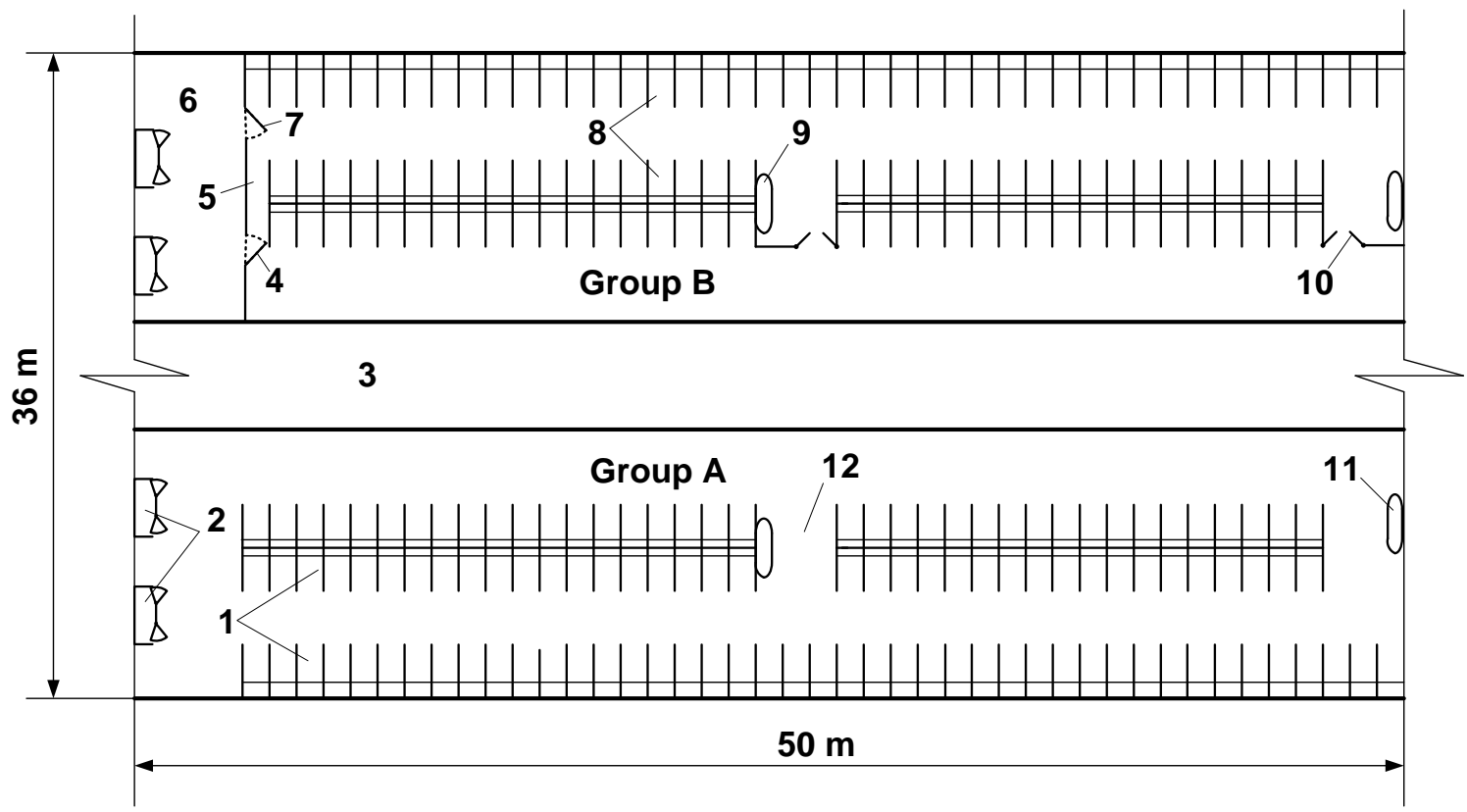

Fig.1. Fragments of the experimental milk cow barn plan: $1 ; 8$ - cow recreation boxes; 2 - AMS ; 3 - feeding table; 4 - cow selection gate; 5 - smart gate; 6 - waiting area; 7 - one-way gate for exit

from the milking zone; 9; 11 - water troughs; 10 - one-way gate; 12 - cross between lying stalls

Beds are fitted with rubber mattress. Every two days the beds are sprinkled with chopped straw. The cows of the group A could move freely along all functional zones, they could also go to AMS. However, they were milked and could get concentrated feed only in case, if before the previous milking the set time interval determined in the milking permission had passed.

The cows of group B could enter the milking zone only through the selection gate 4 . Besides, only if the cow has got the milking permission, i.e., between the separate milkings the pre-set time interval has passed. If there is not such permission, the cow moving through the smart gate gets into the feeding zone where there is the feeding table. In turn, the cows which get into the milking zone can choose the AMS that is not busy at the moment. For the milked cows to exit the milking zone, there is a one-way gate 7 installed. To get to the feeding table they must repeatedly move through the selection gate 4 . By the help of this gate the cows which are not milked completely get back to the milking zone. In turn, the cows which are fed get back to the recreation zone through the one-way gate 10 .

Both groups of cows have access to AMS $24 \mathrm{~h}$ per day, except the time when the milk collection system is washed or maintained. During milking of every cow, the concentrated feed is available, the amount of which depends on the milk yield.

Driving of the "lazy "cows is done by one worker in the barn depending on the work determined by the herd management system. Usually, it is done at the beginning of the shift and in the middle of the 
shift. The milking interval time increase is set for every cow individually by means of computer software considering the expected milk yield. The experiment lasted for 40 days.

\section{Results and discussion}

Table 1 shows the indicators characterizing the groups of cows milked by robots. The data necessary for the research were obtained from the robot management system and after that processed.

Table 1

\section{Description of cow groups}

\begin{tabular}{|l|c|c|}
\hline \multicolumn{1}{|c|}{ Indicators } & Group A & Group B \\
\hline Number of cows in the group & 97 & 96 \\
\hline Milking frequency, milkings· day ${ }^{-1}$ & 2.64 & 2.95 \\
\hline Average permitted milking interval, $\mathrm{h}$ & 7.2 & 7.5 \\
\hline Average milk yield per day, kg & $17.67 \pm 1.52$ & $20.52 \pm 1.25$ \\
\hline $\begin{array}{l}\text { Total average number of robot visits } \\
\text { per day without milking }\end{array}$ & 1.68 & 0.56 \\
\hline
\end{tabular}

As it was mentioned above, the cows in the group A had free access to visit AMS repeatedly after being milked. In turn, the cows of group B could do it only in case, if after visiting AMS they did not leave the milking zone. As our research shows (Fig. 2), in the cow group A repeated visiting of AMS has been shown in $60 \%$ of cases, calculated according to the actual number of milkings. In turn, in group $\mathrm{B}$ this indicator is only $17 \%$. It indicates that in case of controlled cow traffic, the idle visiting of AMS (without milking) is almost four times less. It allows for a possibility to increase the number of cows to be milked by AMS.

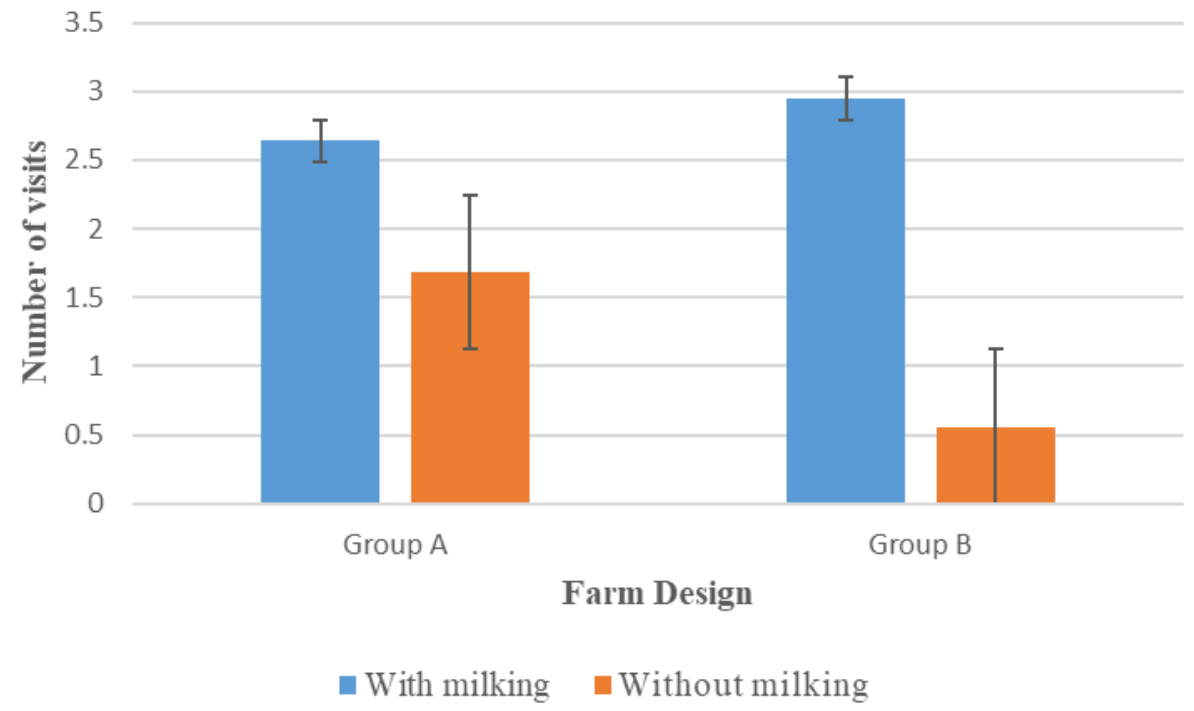

Fig. 2. Total average number of visits to both robots per day

The "lazy" cows, which usually are late for milking, are driven by a worker in the barn. It is usually done twice per day in the period of time approximately from 08.00 to 10.00 and from 20.00 to 22.00 . Driving is done by one person. The average number of driven cows per day and the time consumed for it can be seen in Fig. 3.

With free cow traffic in group A, the average number of driven cows is $16 \pm 7$ (mean \pm SD), but in group B $10 \pm 5$ (mean $\pm \mathrm{SD}$ ) cows per $\mathrm{day}^{-1}$. In turn, the time consumed for driving cows in group A were $36.0 \pm 15.3 \mathrm{~min} \cdot \mathrm{day}^{-1}$, but in group B $20.7 \pm 12.5$ (mean $\pm \mathrm{SD}$ ) min $\cdot$ day $^{-1}$. These data show that the number of driven cows and the time consumed for driving vary quite widely. It can be explained by the professional skills of the driver and his labour intensity. Considering that in the experimental barn there are five groups of cows, the total saving of labour force with the introduction of controlled cow traffic in all groups of cows would be 465 man-hours per year. 


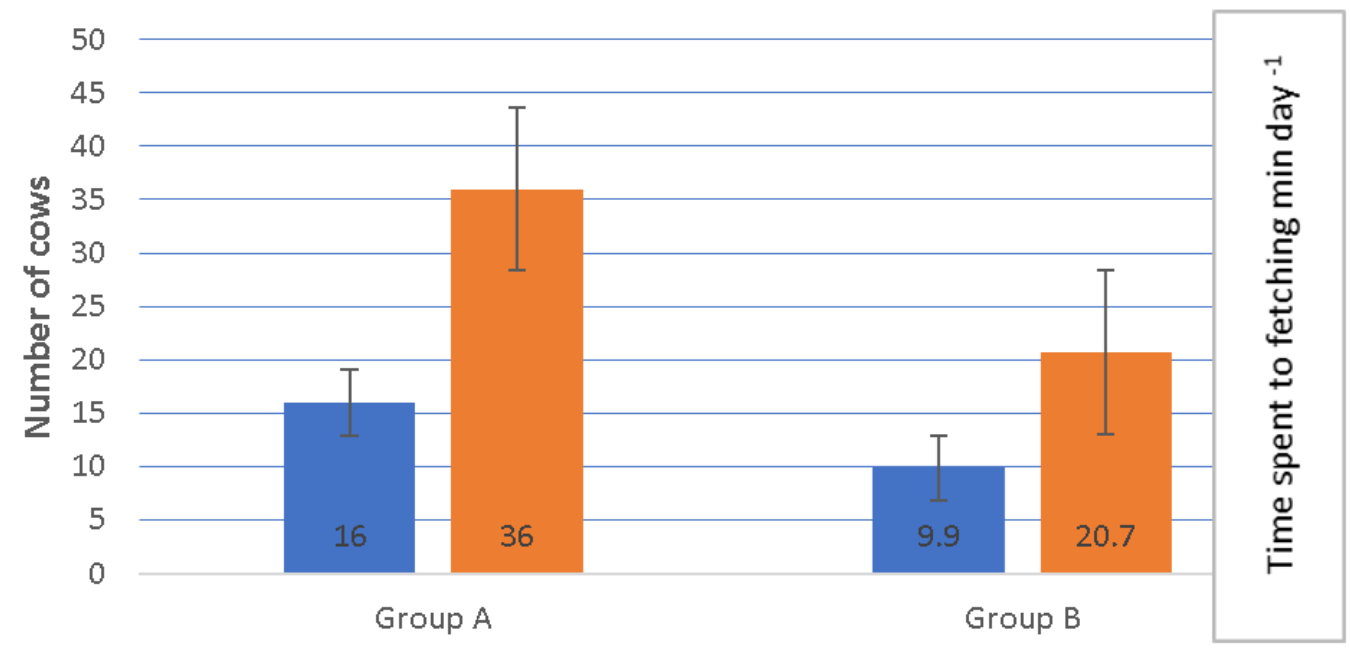

Farm Design

Mumber of cows to be fetched $\quad$ Time spent to fetching

Fig. 3. Average number of cows to be driven per day and time consumed for driving, min $^{-d_{a y}}{ }^{-1}$

\section{Conclusions}

1. If cows are milked by AMS and the free cow traffic system is used, cows are visiting the robots without milking approximately in $60 \%$ of cases, calculating according to the actual number of milkings. If the controlled cow traffic system is used, this indicator is only $17 \%$. It means that the number of repeated visiting of AMS by already milked cows decreases almost four times in case of controlled cow traffic compared to free traffic. It essentially reduces the idle load of AMS.

2. With free cow traffic, the time consumed for driving cows is 2.19 man-hours, calculated per cow per year, but with controlled traffic, using the selection gates, it is 1.26 man-hours per cow per year. It is almost two times less.

3. If in the researched farm in all five cow groups the controlled cow traffic system is introduced, the total saving of the labour force would be 465 man-hours per year.

\section{References}

[1] Jacobs J. A., Siegford J. M. Invited review: The impact of automatic milking systems on dairy cow management, behavior, health, and welfare. Journal of Dairy Science, 95(5), 2012.

[2] Pastell M., Takko H., Grohn H., Hautala M., Poikalainen V., Praks J., Ahokas, J. Assessing cows' welfare: Weighing the cow in a milking robot. Biosystems Engineering, 93(1), 2006, pp. 81-87.

[3] Hamann J., Dodd F.H. Milking Routines. Machine Milking and Lactation. Berkshire, Vermont: Insight Books, 1992, pp. 69-96.

[4] Hogeveen H., Miltenburg J.D., Hollander den S., Frankena K. A Longitudinal Study on the Influence of Milking Three Times a Day on Udder Health and Milk Production. Proceedings of the International Symposium "Robotic Milking", August, 17-19, 2000, Lelystad, Netherland. Wageningen: Wageningen Pers, 2000, pp. 297-298.

[5] Hale S. A., Capuco A. V., Erdman, R. A. Milk yield and mammary growth effects due to increased milking frequency during early lactation. Journal of Dairy Science, 86(6), 2003, pp. 2061-2071.

[6] Soberon, F., Ryan, C. M., Nydam, D. V., Galton, D. M.,, Overton, T. R. The effects of increased milking frequency during early lactation on milk yield and milk composition on commercial dairy farms. Journal of Dairy Science, 94(9), 2011.

[7] Ketelaar-deLauwere C.C., Hendriks M.M.W.B., Metz J.H.M., Schouten W.G.P. Behaviour of dairy cows under free or forced cow traffic in a simulated automatic milking system environment. Appl. Anim. Behav. Sci. 56, 1998, pp. 13-28.

[8] Melin M., Wiktorsson H., Norell L. Analysis of feeding and drinking patterns of dairy cows in two cow traffic situations in automatic milking systems. J. Dairy Sci. 88, 2005, pp. 71-85. 
[9] Hermans G. G. N., Ipema A. H., Stefanowska J., Metz J. H. M. The effect of two traffic situations on the behavior and performance of cows in an automatic milking system. J. Dairy Sci. 86, 2003, pp. 1997-2004.

[10] Harms J., Wendl G., Scho"n H. Influence of cow traffic on milking and animal behaviour in a robotic milking system. Pages II-8-II-14 in Proc. 1st North Am. Conf. Robotic Milking. Wageningen Pers, Wageningen, The Netherlands, 2002.

[11]Bach A., Iglesias C., Calsamiglia S., Devant M. Effect of amount of concentrate offered in automatic milking systems on milking frequency, feeding behavior, and milk production of dairy cattle consuming high amounts of corn silage. Journal of Dairy Science, 90(11), 2007, pp. 50495055.

[12] Hulsen J. Melken mit dem Roboter. Zutphen: Roodbont, 2008, 52 p. (In German)

[13] Laurs A., Priekulis J. Studies of operating parameters in milking robots with selectively guided cow traffic. Agronomy Research 8, 2010, pp. 134-140.

[14] Laurs A., Priekulis J., Purins M. Research in time between milking interval and variability of milking frequency using milking robots In: Proceedings of the 9th International Scientific Conference: Engineering for Rural Development, Jelgava, Latvia, 2010, pp. 101-105.

[15] Kopfmann J. Kuhferkehr: wie läuft's am besten? /Melkroboter Management. Landwirtschaftsverlag GmbH, Münster-Hiltrup, 2012, pp. 40-42. (In German)

[16] Bach A., Devant M., Iglesias C., Ferrer A. Forced traffic in automatic milking systems effectively reduces the need to get cows, but alters eating behavior and does not improve milk yield of dairy cattle. Journal of Dairy Science 92(3), 2009, pp. 1272-1280. 